\title{
Student perspectives on online lectures during the Covid-19 lockdown
}

\author{
David Read ${ }^{\star, 1,2}$, Stephen M. Barnes ${ }^{1}$, and Paul J. Wilson ${ }^{1}$ \\ ${ }^{1}$ School of Chemistry and ${ }^{2}$ Centre for Higher Education Practice, University of Southampton, \\ Highfield, Southampton SO17 1BJ (UK)
}

${ }^{*}$ Corresponding Author: d.read@soton.ac.uk

Keywords: Blended learning; Online learning; Recorded lectures

\begin{abstract}
This article outlines an exploratory study that investigated students' perceptions of the benefits and disadvantages of lecture recordings delivered as part of an introductory chemistry program in the UK during the COVID-19 lockdown in Spring 2020. Three features of these lecture recordings are considered: 1) the production of a series of mini-lectures rather than 50 minute recordings;

2) the inclusion of quiz questions in the video timeline; and 3) the inclusion of a picture-inpicture talking head showing the instructor alongside a captured screen. Analysis of survey data indicates that a majority of students felt that each of these features had a positive impact on their learning and/or experience, with a significant number expressing a preference for the retention of online lectures after the resumption of oncampus teaching. Qualitative data provides valuable insight regarding the specific aspects of the recorded lectures that were perceived to enhance the student experience, supporting the design of future provision both during and beyond the COVID-19 pandemic. The generalizability of the recommendations is also discussed, along with the limitations of the study.
\end{abstract}

\section{Introduction}

The benefits and disadvantages of lecture recording in terms of student learning and engagement have been debated extensively over recent years (Nordmann et al. 2019). The global impact of the COVID-19 pandemic in March 2020 meant that the recorded lecture became a cornerstone of educational delivery on university programs. The closure of campuses at the University of Southampton (UK) necessitated a shift to an online format across programs serving $>20,000$ undergraduate students. This article outlines the delivery model that was adopted on an introductory Chemistry course, with a specific focus on the provision of lecture material in an online format. The design principles applied to the production of online lectures are discussed, with reference to the underpinning literature. An evaluation of the student response is described, with thematic analysis providing valuable insights that support enhancement of online or hybrid learning in the immediate future, and provides evidence that supports the evolution of the delivery model when 'normal' on-campus teaching is resumed. This is intended as an exploratory study that might have value in framing future research projects.

\section{Context}

As discussed previously (Read et al., 2022; Read et al. 2019; Read, Watts \& Wilson, 2016), the Science Foundation Year (SFY) at the University of Southampton provides an entry route onto science degree programmes for students who do not have the required qualifications for direct entry, with a typical cohort size of 40-60. Prior to the pandemic, the SFY chemistry module featured 3 chemistry 
lectures per week and a workshop session (15-20 students) that included collaborative group activities as well as worksheet-based problem sets, with a staff member and two demonstrators present. Students are provided with gapped handouts (Morgan, 2003) that they complete during the session. Lectures are delivered via PowerPoint, with on-screen annotation used to add text, equations, mechanisms etc. All in-person lectures are recorded using Panopto (https://www.panopto.com/). Around $40 \%$ of lectures are supported by a previously reported semi-flipped approach (Read et al., 2016). This involves the delivery of a $\sim 15$ min segment of a lecture in the form of a pre-lecture video that frees up precious face-to-face time for active learning.

A key finding of this study was that a majority of students reported increased confidence to participate in Q\&A and discussion with peers as a result of the semi-flipped approach. Bokosmaty et al. (2019) used a similar approach to enhance in-class sessions through active learning opportunities including guided-inquiry worksheets and clickers to promote discussion. Furthermore, Ranga (2020) demonstrated that engagement with pre-class materials in a semi-flipped approach enhanced student engagement with interactive problem-solving in class. Such interactivity is a key feature of chemistry lectures on our program and is supported by the semi-flipped approach. The rapid shift to online learning meant the loss of valuable opportunities to actively engage students in their learning during lectures. In order to adapt, we drew on approaches detailed in the literature.

\section{Design principles}

The option of posting recordings of a previous year's lectures was ruled out, as we felt these were unsuitable for online teaching. As noted by Nordmann et al. (2020), features such as inaudible dialogue and references to assessments, create incongruencies that necessitate the creation of bespoke lecture recordings tailored to online study. The length of such recordings is a key concern, with the ' 6 minute rule' often cited as a guideline, based on an analysis of student engagement with videos in Massive Open Online Courses (MOOCs) (Guo, Kim \& Rubin, 2014). This study involved analysis of data relating to $6.9 \mathrm{~m}$ video watching sessions and found that the normalized engagement time (i.e. the proportion of a video that students actually watched) decreased as the length of the video increased, with a significant drop beyond 6-9 minutes. There is some scepticism about the veracity of this so-called 'rule', with Lagerstrom (2015) referring to the 'myth of the 6 minute rule' in a similar study that found that students spent a mean of 17-20 minutes watching longer videos (50-75 minutes); students generally viewed the entire video, but were choosing to watch it in segments. Although Lagerstrom's results indicated that students were able to proactively control the flow of material when watching a recording, it has been suggested that novice learners in particular lack the knowledge and metacognitive skills to know when best to pause videos to reflect and consolidate (Fiorella \& Mayer, 2018). Brame (2016) also suggested that shorter videos addressing specific learning goals helped students to manage intrinsic cognitive load. With this in mind, and in the absence of definitive evidence about the optimum length for recordings in online courses, we opted to break each lectures into three segments, each approximately 12-18 minutes in duration, focusing on specific concepts.

The aforementioned interactivity of face-to-face lectures on the program is mediated through frequent use of in-class 'clicker'-style voting using Vevox (https://www.vevox.com/) to test understanding and promote active learning through student-student and student-instructor dialogue, often through Mazur's 'Peer instruction' approach (Crouch \& Mazur, 2001; Schell \& Mazur, 2015). While it is unfeasible to introduce peer-to-peer interaction into recorded lectures, some level of interactivity was desirable. Panopto allows the inclusion of quiz questions in the video timeline, and previous research by Szpunar et al. (2013) on 'interpolated testing' suggests this is beneficial in discouraging mind wandering and encouraging task-relevant activity. Jing et al. (2016) defined interpolated testing as a form of retrieval practice whereby students engage with questions interspersed within a recording, as is the case when questions are added in Panopto, rather than after the event. This 
'testing effect' had been identified by Roediger and Butler (2011) as playing a critical role in long-term retention, providing additional justification for the addition of quiz questions to recordings. Furthermore, Butler et al. (2008) suggest that providing feedback after retrieval practice has occurred is important in consolidating learning for those who answered correctly and enables others to correct their metacognitive errors. It was decided that 3-5 quiz questions would be incorporated into each mini-lecture, with feedback provided in text form, as well as verbally in the form of a short explanation by the instructor, after each question. It should be noted that quiz questions interspersed within these mini-lecture recordings also serve as break points within content delivery, acting to provide additional segmenting of the material, with students effectively controlling progression to the next segment by clicking to continue after reading the text feedback.

A final concern was whether or not to include a talking-head (or 'picture-in-picture') video showing the instructor alongside the PowerPoint content. The role of this form of instructor presence in supporting student learning from videos has been investigated previously with mixed results. In a recent study, Wang et al. (2020) suggested that there may be benefits in terms of student satisfaction and situational interest when online videos feature instructor presence. However, an earlier review of the literature by Mayer (2014) indicated that the inclusion of an image of the instructor does not lead to a significant positive effect on learning. In fact, it was suggested that it may be detrimental to learning, since watching the instructor rather than looking at slide content can waste cognitive processing capacity.

Chemistry instructors on the SFY make extensive use of props and hand gestures during lectures, hence it was decided that lectures would be presented with a talking head displayed on screen, but that signalling techniques (Van Gog, 2014) (i.e. the laser pointer feature within PowerPoint) would be used to direct students' attention to key visual content to mitigate the split-attention effect (Ayres \& Sweller, 2005) that might arise if students are fixated on the talking head. Mayer and Moreno reported that similar difficulties arise from the presentation of pictorial and textual information simultaneously, leading to students focusing on nonessential facts or features of the graphics (Mayer \& Moreno, 2003). Given that this is a feature of the slides used in these lectures, signalling was felt to be crucial in ensuring that students were looking at the relevant features of the visual material throughout each recording.

\section{Methodology}

\section{Preparation and delivery of material}

The University of Southampton closed its campuses in mid-March 2020. At this point, students had completed the first 7 weeks of semester 2, with 4 weeks remaining. Lecture recordings were prepared in line with the design principles outlined previously. Of the 12 lectures remaining to be delivered, 11 were broken into three mini-lectures and the other into 4 parts. Quiz questions were added to each mini-lecture at key points to test understanding of concepts as they were covered (see Figure 1 for an example). After students submitted each answer, they received text-based feedback stating the correct answer and a brief explanation. Additionally, a verbal explanation of the answer was given by the instructor in the video timeline.

Mini-lectures were made available via the virtual learning environment (Blackboard) each Friday afternoon, along with gapped handouts in PDF and PowerPoint formats for students to download and annotate. Students were able to attend 'office hours' sessions (MS Teams) on Monday and Tuesday in which they could ask questions about lecture material. On Friday, an interactive online one-hour workshop was scheduled (MS Teams), featuring in-session voting on questions relating to the week's material. The instructor was able to view data on the completion of Panopto quiz questions and the correctness of responses, providing the opportunity to give general feedback on performance. These sessions helped to establish a routine for students, whereby they were encouraged to stay up to date with content. The weekly schedule of activity experienced by the students during the period of online learning is illustrated in Figure 2. 


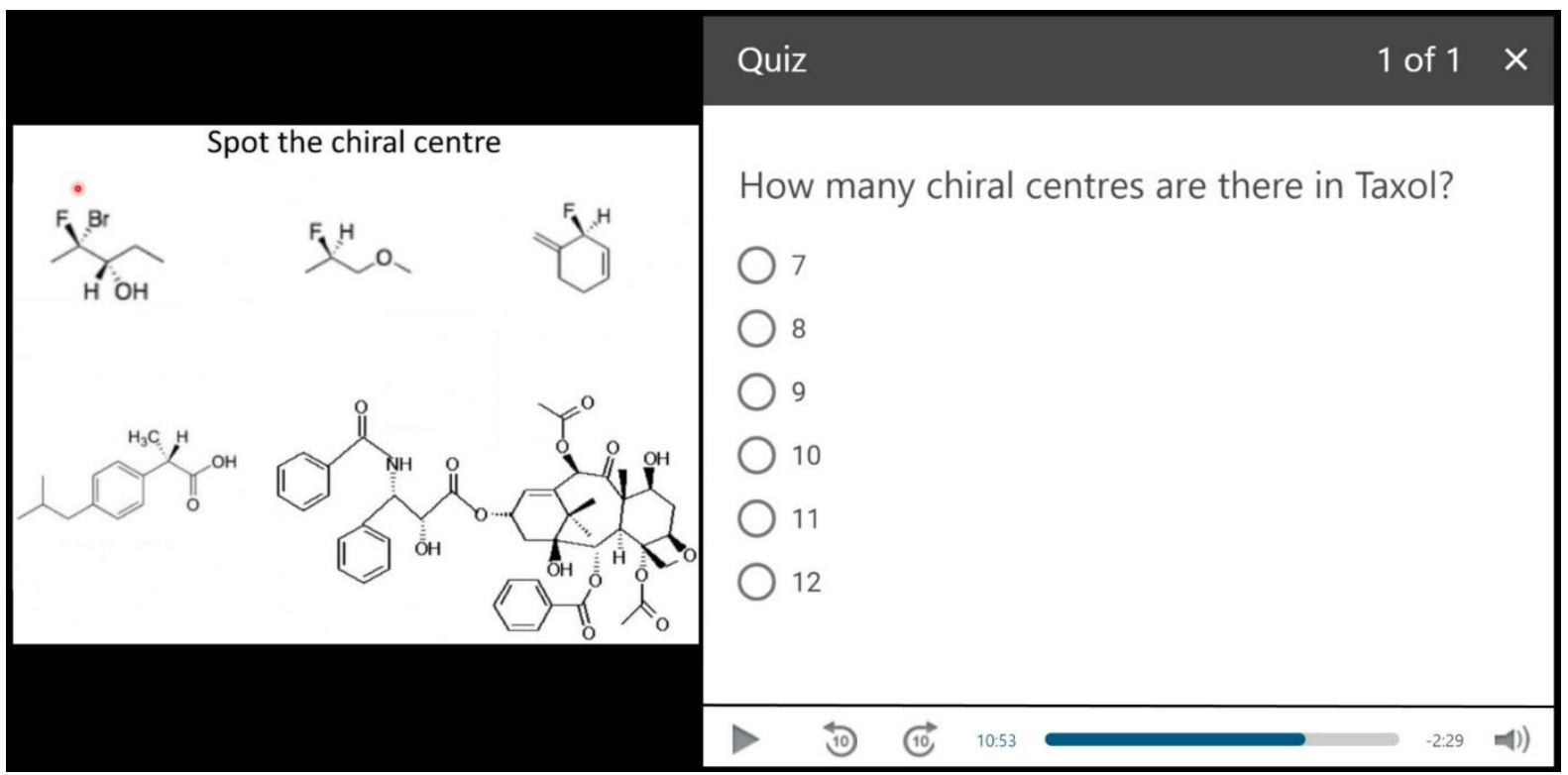

Figure 1 An example Panopto quiz question testing the ability of students to assign chiral centers in skeletal structures.
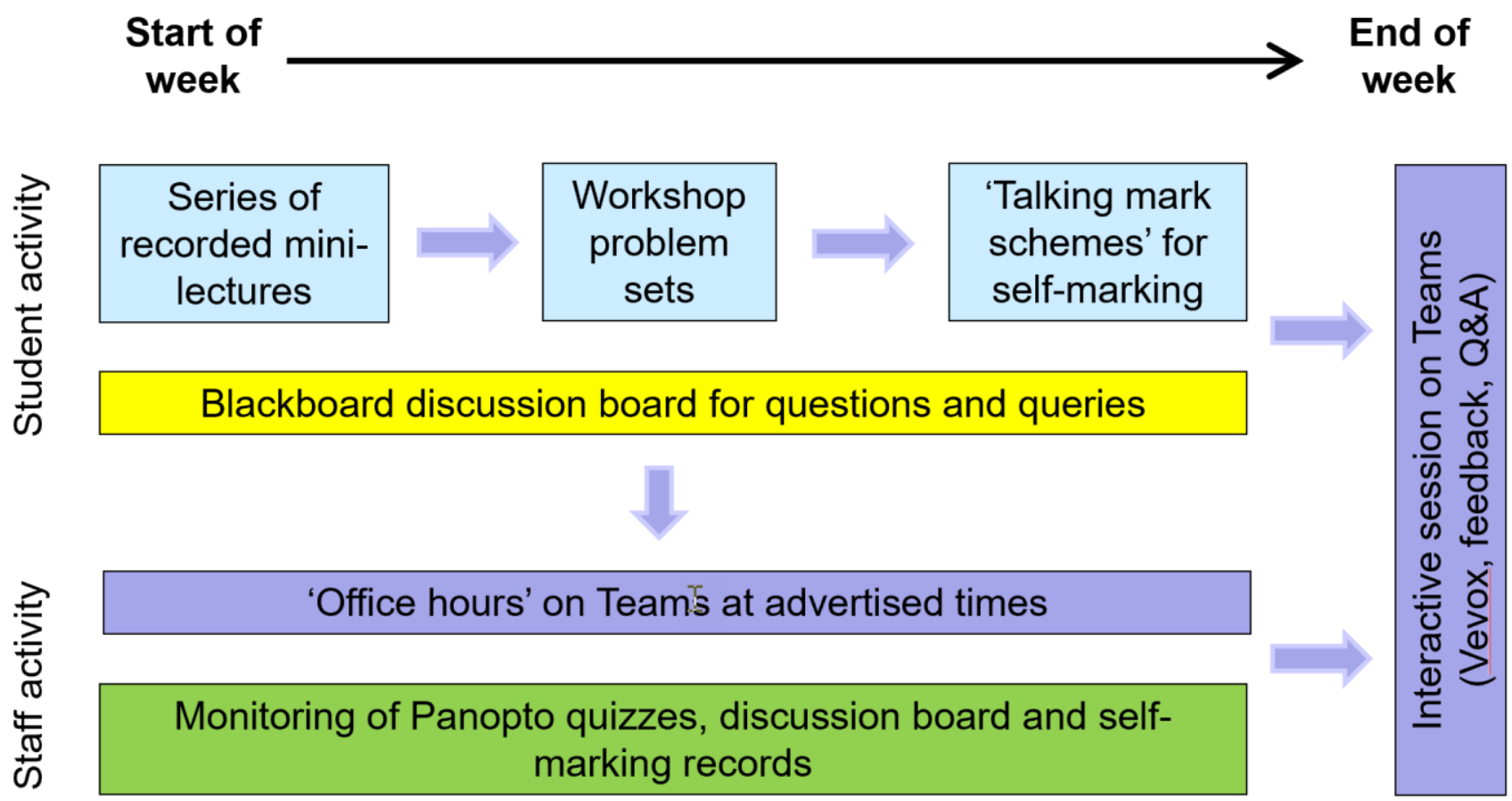

Figure 2 Weekly schedule of activity for students undertaking the chemistry module on the Science Foundation Year program during April/May 2020, when all teaching had been moved online.

\section{Survey design}

As asserted by Schacter and Szpunar (2015), it is important that research is carried out to investigate the factors that influence student attention to, and retention of, recorded lecture content. We also felt that it was important to collect students' views on the quality of the online provision on the Science Foundation
Year program during the period of online learning to support the evaluation process. The design of the survey and the subsequent analysis of data collected were informed by the following guiding research questions:

1) What are students' perceptions of the benefits and disadvantages of the 
Student perspectives on online lectures during the Covid-19 lockdown

online learning approaches implemented on the Science Foundation Year in April/May 2020 in terms of (a) their experience and (b) their learning?

2) What are students' opinions about the continued use of some of these approaches once we return to on campus teaching?

The draft survey was piloted with a former SFY student now studying on their degree programme, leading to minor changes to the wording of some questions. Ethical approval for the revised survey was obtained via the University of Southampton's Ethics and Research Guidance Online portal (ERGO \#56867), and a link was sent to all students on the program via email in the final week of teaching. Participation was voluntary and all data were collected anonymously. Students were also informed about the survey and the purpose of the study during a synchronous online session. Responses were collected over a two-week period, with a reminder sent to students before the deadline. Of 52 enrolled students enrolled, 23 submitted responses.

This article is concerned with the data specifically relating to lecture material. The survey included other questions relating to the provision of workshop content and other logistical aspects of online delivery, which are not discussed here.

\section{Data analysis}

Students' responses to Likert-style questions and prompts were tabulated and are presented in Table 1. Most Likert-style questions were followed by an open-text response prompt asking students to explain their answer, resulting in short comments that were analyzed in Microsoft Word. The qualitative data were subjected to thematic analysis (Braun \& Clarke, 2006), initially by the corresponding author, using an inductive approach, whereby all responses to each question were read several times to identify themes that occurred in multiple students' responses. These were attributed using color coding of the text in Microsoft Word, similar to an approach used in Microsoft Excel by Bree and Gallagher (2016). This was repeated several times, with related themes being clustered under broader themes.
The entire raw data was then examined by the second author in a similar manner. These authors then held a discussion to carry out further consolidation under the broad themes listed in Tables 2-5, which were deduced in consensus and are accompanied by extracts from students' comments.

\section{Results and discussion \\ The benefits and disadvantages of mini- lecture recordings vs 'normal' lectures}

A majority of respondents reported that the provision of shorter lecture recordings had a positive impact on their learning. Thematic analysis (Table 2) indicated that the "control and flexibility' over when recordings were watched and the pace of progression through content was important. Several students reported that the approach allowed them to focus on key content and take time to think about concepts before moving on ('focus and consolidation'). Another theme was that the approach permitted enhanced note-taking compared with in-person lectures and that they had more time for organization and subsequent revision ('augmentation and organization'). A number of students referred to 'problems with in-person lectures', where content felt rushed in comparison and there were more distractions. A key comment was that if a concept is not understood early in a lecture, the student can then feel lost afterwards; whereas in an online lecture, they can take remedial action before moving on. The small number of students who gave negative responses cited the lack of an opportunity to ask questions and that they missed the 'personal experience'.

\section{The benefits and disadvantages of quiz questions in lecture recordings}

In considering this data, our assumption is that all students answered all questions, since they were not permitted to advance without submitting an answer. Again, the majority of respondents reported that in-lecture quiz questions had a positive impact on their learning. Thematic analysis (Table 3 ) showed that several students felt this helped to engage them more in the learning process and ensured they maintained attention ('engagement and focus'). 


\begin{tabular}{|c|c|c|c|c|c|}
\hline \multirow[b]{2}{*}{ Question } & \multicolumn{5}{|c|}{ No. of students selecting category ${ }^{a}(n=23$ ) } \\
\hline & $\begin{array}{l}\text { Sig } \\
+ \text { ve }\end{array}$ & $\begin{array}{c}\text { Small } \\
+\mathrm{ve}\end{array}$ & $\begin{array}{c}\text { No } \\
\text { impact }\end{array}$ & $\begin{array}{c}\text { Small } \\
- \text { ve }\end{array}$ & $\begin{array}{l}\text { Sig } \\
\text {-ve }\end{array}$ \\
\hline $\begin{array}{l}\text { Q1a) What do you feel is the impact of shorter mini-lecture } \\
\text { recordings on your learning in comparison to a } 50 \text { minute face- } \\
\text { to-face lecture? }\end{array}$ & 8 & 9 & 3 & 3 & 0 \\
\hline $\begin{array}{l}\text { Q2a) What do you feel is the impact of the inclusion of } \\
\text { Panopto quiz questions on your learning in comparison to } \\
\text { recordings with no quiz questions (e.g. flipped lectures from } \\
\text { earlier in the year)? }\end{array}$ & 8 & 12 & 2 & 1 & 0 \\
\hline $\begin{array}{l}\text { Q3a) What is the impact on your experience of providing a } \\
\text { "talking head" showing the lecturer in a recording in } \\
\text { comparison to recordings with no "talking head"? }\end{array}$ & 5 & 11 & 7 & 0 & 0 \\
\hline $\begin{array}{l}\text { Q4a) What is the impact on your experience of us providing } \\
\text { lectures in an online format in comparison to attending face-to- } \\
\text { face lectures on campus? }\end{array}$ & 5 & 5 & 4 & 6 & 3 \\
\hline Question & $\begin{array}{c}\text { Strongly } \\
\text { agree }\end{array}$ & Agree & Neutral & Disagree & $\begin{array}{l}\text { Strongly } \\
\text { disagree }\end{array}$ \\
\hline $\begin{array}{l}\text { Q5a) To what extent do you agree with the following } \\
\text { statement? } \\
\text { Lecture material should continue to be provided in the current } \\
\text { format (i.e. online mini-lectures with Panopto quiz questions) } \\
\text { when we return to on-campus teaching }\end{array}$ & 5 & 5 & 6 & 5 & 2 \\
\hline
\end{tabular}

a Students responded to questions Q1a) - Q4a) using a Likert-type scale with the options: significant positive impact, small positive impact, no impact, small negative impact and large negative impact

Table 1 Counts of students' responses to Likert-style survey questions.
Theme (benefit to student) ${ }^{a}$
Extracts of illustrative quotes from students
Control and flexibility
"...do at a time that works, when you are fully engaged."
"...allows me to do this at my own pace."

Focus and consolidation

Augmentation and organization

Problems with in-person lectures “...think about what I had just watched. I found this aided my understanding." "...allows me to take a break and think for as long as I need about what I have just been taught."

"...take notes in more detail than usual and spend more time on organizing them which makes revision easier."

“...complete a brief note...before moving on... I compile these notes together to get a deeper understanding"

“...in a one hour lecture a lot of the material can be rushed and there's not enough time to think."

"If you don't get a concept early on you could well be lost."

"...less distracted than when doing longer lectures (where) i find myself not paying as much attention"

a The 3 respondents who gave a negative response to Q1a identified the following disadvantages: lack of personal interaction, inability to ask questions, and the fact that the mini-lectures were still 15-20 mins long.

Table 2 Thematic analysis of students' explanations of their responses to Q1a: What do you feel is the impact of shorter mini-lecture recordings on your learning in comparison to a 50 minute face-to-face lecture? (19 responses). 
Student perspectives on online lectures during the Covid-19 lockdown
Theme (benefit to student)
Extracts of illustrative quotes from students
Engagement and focus
"...think about and practice a topic during the learning. I feel it engages me more."
“...these questions push me to pay attention."

"...to feel that I have grasped the concept or not as the case may be."

Monitoring understanding

"...see when you don't understand something straight away and go back and fix that before you move on."

"Getting the answers right also gives me a sense of achievement."

"When the questions are answered correctly this is very encouraging and provides a

Motivation and achievement sense of achievement."

"...the pressure of knowing that the lecturer will see the results makes me more attentive and want to do better."

Problems with 'normal' recorded/flipped lectures “...it is easy to (lose focus) when watching pre-recorded lectures."

"With flipped lectures that didn't have questions I was never quite sure I understood the material till the following lecture."

a The 3 respondents who gave neutral/negative response to Q2a noted that the presence of quiz questions made it difficult to navigate through lectures when reviewing them later on, and that not knowing the answers caused stress.

Table 3 Thematic analysis of students' explanations of their responses to Q2a: What do you feel is the impact of the inclusion of Panopto quiz questions on your learning in comparison to recordings with no quiz questions? (20 responses).

\begin{tabular}{|c|c|c|}
\hline \multicolumn{2}{|r|}{ Theme } & Extracts of illustrative quotes from students \\
\hline \multirow{2}{*}{ 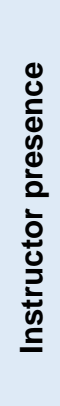 } & $\begin{array}{l}\text { Authenticity and } \\
\text { involvement }\end{array}$ & $\begin{array}{l}\text { "It feels more like an actual lecture compared to flipped lectures." } \\
\text { "...it almost appears like a real/live lecture that feels much more interactive..." } \\
\text { “...felt like I was actually in a lecture so I was more motivated to work." }\end{array}$ \\
\hline & Personal element & $\begin{array}{l}\text { "...important to see the face of the lecturer to feel involved because eye contact is necessary." } \\
\text { "It's nice to feel like a teacher is there." } \\
\text { "I found that although the "talking head' made the lectures seem more personal, I don't think it } \\
\text { increased my understanding of the content" }\end{array}$ \\
\hline \multirow{2}{*}{ 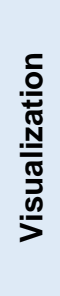 } & Hand gestures & $\begin{array}{l}\text { "Seeing hand movements etc make the video feel more real" } \\
\text { "...beneficial for lecturers like David who uses his hands when explaining the collusion (sic) of } \\
\text { molecules or transfer of electrons from one molecule to another." }\end{array}$ \\
\hline & Use of props & $\begin{array}{l}\text { "Sometimes useful like when David used molecular models and could hold them up." } \\
\text { "props used in the explanations of content is very helpful in visualising ideas" }\end{array}$ \\
\hline
\end{tabular}

Table 4 Thematic analysis of students' explanations of their responses to Q3a: What is the impact on your experience of providing a 'talking head' showing the lecturer in a recording in comparison to recordings with no 'talking head' (e.g. flipped lectures from earlier in the year)? (15 responses). 
Student perspectives on online lectures during the Covid-19 lockdown

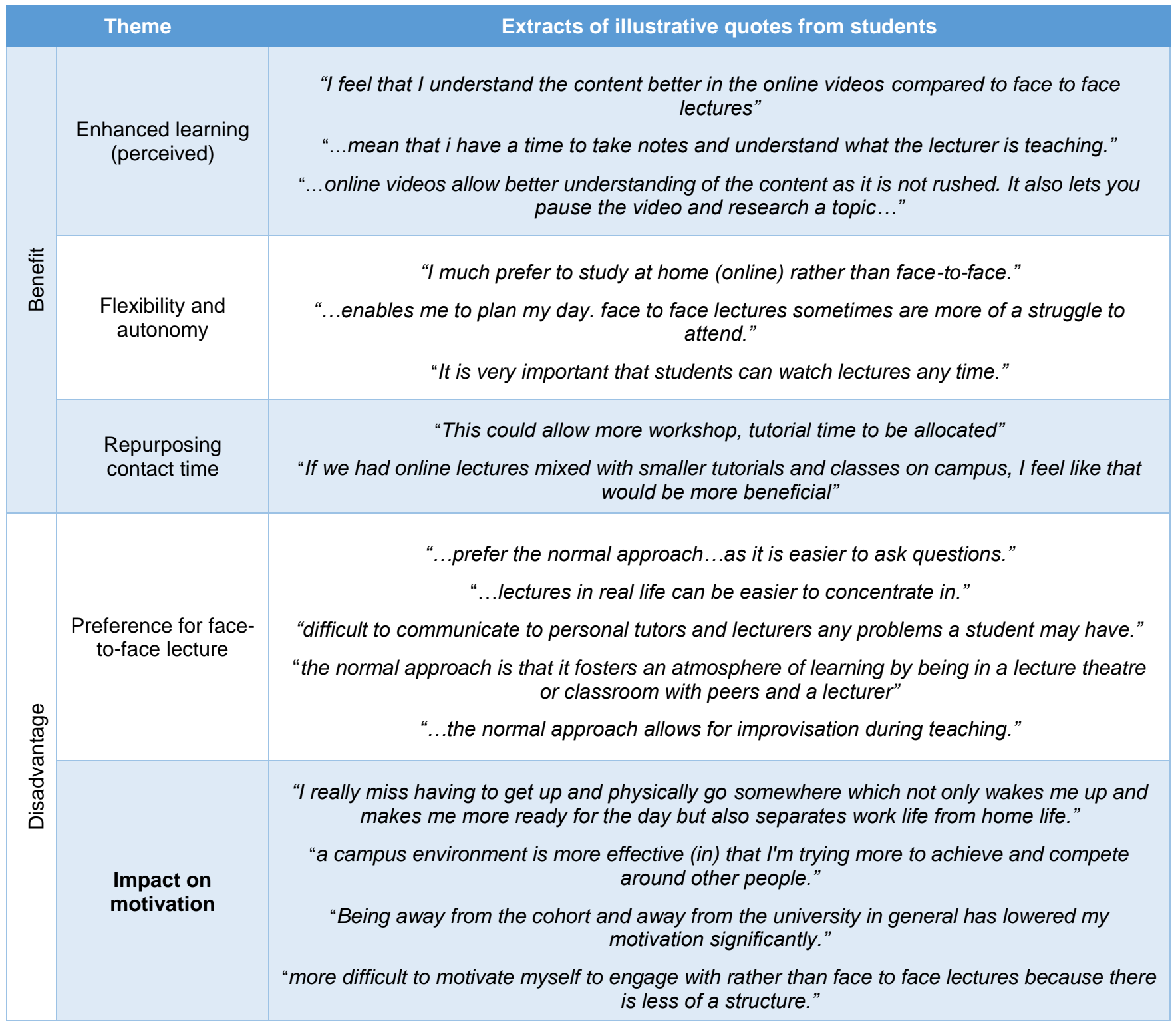

Table 5 Thematic analysis of students' explanations of their responses to Q5a: To what extent do you agree with the following statement? "Lecture material should continue to be provided in the current format (i.e. online mini-lectures with Panopto quiz questions) when we return to on-campus teaching?"(17 responses).

Another important theme was that the approach supported 'monitoring understanding', with the point made that an incorrect answer was a prompt to correct the misunderstanding before proceeding. Several students mentioned that answering questions correctly provided a sense of achievement, with some suggesting that visibility of responses to staff encouraged them to try to do well ('motivation and achievement'). Some students made a direct comparison with recordings that lacked quiz questions, noting a tendency to lose focus and uncertainty regarding their grasp of the material. Students who gave neutral or negative responses cited discomfort at being expected to answer questions on material they had only just encountered.

\section{The benefits and disadvantages of a 'talking head' showing the lecturer}

Q3a) was deliberately phrased as relating to the impact on students' experience rather than their learning, given the literature view that there is little evidence of impact on learning (Mayer, 2014; Wang et al., 2020). The majority of respondents reported that the provision of a 'talking head' had a positive impact on their 
experience in comparison with videos without a talking head, with none reporting a negative impact. Thematic analysis (Table 4) identified an overarching theme of 'instructor presence', with numerous students stating that it felt more like a 'real' lecture, and that this promoted a sense of 'involvement', classified under 'authenticity and involvement'. A distinct point made by some students was that the presence of a talking head helped to provide a "personal element', with the suggestion that it felt like the teacher was present and was more like a faceto-face experience. The other overarching theme was 'visualization', with several students indicating that being able to see 'hand gestures' was important, particularly where these were used to communicate concepts. Similarly, numerous students reported the value of the 'use of props', such as molecular models, to assist with the visualization of key concepts. It should be noted that it is possible that students' perceptions about the value of the talking head may have been skewed by the fact that they were already familiar with the instructor and their teaching style, although the comments indicate that there are benefits that are transferrable to other instructors.

\section{The impact of online lectures vs attended in-person lectures on their experience}

Interestingly, responses to Q4a) were more polarized than in the other cases, with similar numbers of students reporting positive and negative impacts on their experience. This is notable as those who responded negatively had mostly given positive or neutral responses to previous question, indicating that some see potential benefits in the role of online lectures and the design features implemented, but that something important is missing in terms of their experience without in-person contact. Thematic analysis of responses relating to $\mathrm{Q} 4 \mathrm{a}$ ) is not reported here as there is significant overlap with those relating to Q5a). Students who reported a positive impact referred to benefits identified in response to the previous questions, while students who reported a negative impact referred to the following issues: missing the requirement to physically travel to university and the separation of work and home life; missing the competitive nature of having peers around them; tending to zone out and switch off without having a lecturer present to focus attention; and reduced motivation.

\section{The student view regarding the continuation of online lectures when on- campus teaching is resumed}

Responses to Q5a) were also polarized, although more students agreed that online lectures should continue than disagreed. Analysis of responses from those agreeing with the statement identified three key themes (Table 5): 'Enhanced learning (perceived)' including comments about note taking and augmentation; 'flexibility and autonomy' referred to the ability to self-organize study time and control the pace; and 'repurposing contact time' related to suggestions for how face-to-face time could be better utilized. A significant proportion of respondents appear to see the potential value of this approach during 'normal' times, providing a compelling rationale for further research into online lectures as the primary means of delivering content.

It should be noted that the survey question included the caveat 'Note that if we were to continue to provide lecture material in video format, the idea would be to keep timetabled slots for different types of activity rather than lecture delivery.' Despite this, numerous students who disagreed with the statement gave responses indicating they had considered the question in a context where face-to-face teaching was absent. Many of the issues raised would be mitigated by the fact that different forms of face-to-face teaching would replace lectures in the timetable in a more authentic 'flipped classroom' approach, as originally outlined by Bergmann and Sams (2012). However, analysis of these responses is still valuable in providing insights regarding the student experience during lockdown and informing the design of face-to-face teaching that replaces lectures in a flipped model. Analysis of responses from students who disagreed with the statement identified two key themes; a 'preference for face-to-face' resulted from issues around lack of contact with instructors and peers, the inability of the instructor to improvise and reduced concentration levels, while 'impact on motivation' encompassed issues with the lack of structure, routine and variety when teaching is delivered entirely online. 


\section{Implications for practice}

Given the continuing nature of disruption to education as a result of the pandemic at the time of writing, the findings reported herein add to the evidence base informing the design of methods for the delivery of lecture content in a potentially socially-distanced world, as well as after the Covid-19 situation has passed. This section also draws on the findings of other recent studies to frame the recommendations and postulate about their generalizability.

An initial consideration when implementing enforced 'emergency' online teaching is whether lecture material should be provided in synchronous or asynchronous form. Jeffery and Bauer (2020) reported that students found it more difficult to maintain attention during synchronous online lectures than in in-person lectures, while Lee (2020) Burnett et al. (2020) and Petillion \& McNeill (2020b) suggested that asynchronous online lecture content provides learning benefits compared with synchronous online lecture delivery, with the latter noting similar advantages to those identified in the present study i.e. flexibility, control of pace, and the ability to review content. Additional benefits reported by our students include increased scope to augment and organize lecture notes. It should be noted that our students were comparing their experience of online asynchronous lecture recordings with inperson lectures attended earlier in the year, with their views suggesting that the former may continue to have a place in our teaching when normality returns, albeit with a number of caveats.

A common theme across many recent studies, including our own, is that the loss of contact with teaching staff and peers is detrimental to the student experience during an emergency shift to online learning. Jeffery and Bauer (2020) reported that learning was compromised for some students by the loss of structure, as also found in the present study in which some students suggested that the lack of a requirement to attend campus-based sessions and the loss of interaction with others was detrimental to motivation. These findings suggest that instructors should consider how to provide a structure for online learning and opportunities for interaction and collaboration between students during times of enforced online learning.

The main value of the present study is in informing us about the features of online lectures that students perceive to enhance their experience and their learning, helping us to evaluate the benefits and disadvantages of a future move to fully-online lectures in a flipped model. Our finding that students prefer recorded lectures to be broken into minilectures is corroborated by a number of other studies. Reports by both McCusker \& Mohseni (2020) and Kollalpitiya (2020) suggested that students were unable to maintain attention during long recorded lectures. Sarju (2020) adopted shorter recordings to support the management of cognitive load, and found that these were valued by student, who viewed them in preference to full lecture recordings from a previous year that were also provided.

An argument against breaking lectures up given by some colleagues at our institution is that recorded lectures give students full control over the flow of content, and therefore such chunking is unnecessary. While this may be a reasonable assumption when dealing with more senior students, the assertion by Fiorella and Mayer (2018) that novice learners are unable to identify when they need to pause a video to reflect and consolidate their learning suggests that chunking of lecture material is a supportive strategy that should be considered when designing online lectures. However, it should also be noted that some Southampton students have reported feeling overwhelmed when faced with multiple shorter lecture recordings, highlighting a need for further research in this area.

Our students identified numerous benefits of quiz questions in lecture recordings. Szpunar's description of interpolated testing as a proactive restructuring of the learning environment that reduces mind-wandering (2017) correlates with our students' view that the questions encouraged attention. Other benefits cited, including the ability to monitor understanding and feelings of motivation and achievement, may be seen to justify the effort expended in adding such questions. An additional benefit to the instructor is access to students' responses to questions, which may 
support feedback provision and the design of support teaching.

The positive response in the present study provides a compelling case for the inclusion of a 'talking head', particularly at a time when instructor-student interactions are restricted, with the instructor's presence helping to create a sense of authenticity that supports a sense of involvement. Further support comes from Wang and Antonenko (2017), who found that instructor presence in instructional video led to positive impacts on perceived learning, satisfaction, and mental effort; all essential factors that contribute to motivation and engagement. As discussed by Flood et al. (2015), hand gestures and bodily motion bring sub-microscopic entities to "illusory presence", allowing the enactment of their motion and facilitating the depiction of three-dimensional phenomena. Gilbert (2008) described gesture as being a "prevalent, yet almost completely unresearched form of 3D representation" (p. 9), that had been shown by Roth and Welzel (2001) to be particularly useful in conveying scientific phenomena in the absence of a secure grasp of technical language, suggesting that gesture may help to clarify meaning when sub-microscopic processes are being described. Petillion and McNeil (2020a) identified a similar positive student response when evaluating the impact of instructional videos that were centred on the instructor and were developed around the framework of Johnstone's Triangle (Reid, 2019) as part of a study into the flipped classroom in chemistry, which also found evidence of a positive impact on attainment.

\section{Limitations}

Although the response rate was reasonable for a survey of this nature (44\%), a number of students did not respond. It is likely that some non-respondents had not accessed all of the recordings when the survey was distributed and chose not to respond. As discussed by Brecht in relation to 'non-response bias' (2012), it is possible that some students that did not respond actually did view the recordings and thought they had little value. Hence it should be acknowledged that some non-responders may have had neutral or negative views of the provision that are not reflected herein.
Panopto provides extensive data relating to viewing statistics which would have been useful to include in this study. However, a number of students reported problems streaming lectures early on in lockdown, prompting them to download recordings and watch them offline. The resulting inconsistencies in the data make it difficult to draw meaningful conclusions and such an analysis was not attempted for the purposes of this study.

This study provides insight into students' perceptions of the impact of recorded lectures on their learning and experience during the pandemic. Students were cognizant of the fact that the online learning provision had been put together rapidly under pressure and may therefore have reacted more positively than might have been the case had they been presented with online lectures in the absence of face-to-face contact under different conditions.

Due to the anonymity of the survey, there was no way to correlate students' responses with their attainment level or other measures of participation and engagement in the course over the academic year. Attainment level may play a role in a student's attitude towards online lectures, as demonstrated by Li (2019), who found that higher knowledge students tended to feel more positive, perhaps as a result of having better strategies for viewing and learning from videos.

The qualitative data collected are limited in scope and only provide snapshots of students' perspectives on their experience of studying remotely in this way. Where students have indicated that their learning has been enhanced, it is not clear how and why this occurred. Deeper insights could be obtained by holding focus groups or carrying out interviews with students, or designing quasi-experimental studies that compare learning in experimental and control groups using an appropriate instrument.

The outcomes from this work align with the findings of previous studies in numerous aspects, providing some confidence that they are generalizable to other contexts. However, it cannot be ruled out that familiarity with the 
Student perspectives on online lectures during the Covid-19 lockdown

instructor may have influenced some responses and others should carry out an evaluation if implementing any of the recommendations described herein.

\section{References}

Ayres, P. \& Sweller, J. (2005). The splitattention principle in multimedia learning. The Cambridge handbook of multimedia learning, 2, 135-146. https://tinyurl.com/43ad953t

Bergmann, J. \& Sams, A. (2012). Flip your classroom: Reach every student in every class every day: International society for technology in education. https://tinyurl.com/34wubzvk

Bokosmaty, R., Bridgeman, A. \& Muir, M. (2019). Using a Partially Flipped Learning Model To Teach First Year Undergraduate Chemistry. Journal of Chemical Education, 96(4), 629-639. DOI: 10.1021/acs.jchemed.8b00414

Brame, C.J. (2016). Effective Educational Videos: Principles and Guidelines for Maximizing Student Learning from Video Content. CBE-Life Sciences Education, 15(4), es6. DOI 10.1187/cbe.16-03-0125

Braun, V. \& Clarke, V. (2006). Using thematic analysis in psychology. Qualitative research in psychology, 3(2), 77-101. DOI: 10.1191/1478088706QP063OA

Brecht, H.D. (2012). Learning from online video lectures. Journal of Information Technology Education, 11(1), 227-250.

https://tinyurl.com/66hbvxws

Bree, R.T. \& Gallagher, G. (2016). Using Microsoft Excel to code and thematically analyse qualitative data: a simple, costeffective approach. All Ireland Journal of Higher Education, 8(2). https://tinyurl.com/rzr25u3t

Burnett, J.W., Burke, K.A., Stephens, N.M., Bose, I., Bonaccorsi, C., Wade, A.M. \& Awino, J.K. (2020). How the COVID-19 Pandemic Changed Chemistry Instruction at a Large Public University in the Midwest: Challenges Met, (Some) Obstacles Overcome, and Lessons Learned. Journal of Chemical
Education, 97(9), 2793-2799. DOI: 10.1021/acs.jchemed.0c00761

Butler, A.C., Karpicke, J.D. \& Roediger III, H.L. (2008). Correcting a metacognitive error: feedback increases retention of lowconfidence correct responses. Journal of Experimental Psychology: Learning, Memory, and Cognition, 34(4), 918. DOI: 10.1037/02787393.34.4.918

Crouch, C.H. \& Mazur, E. (2001). Peer instruction: Ten years of experience and results. American journal of physics, 69(9), 970-977. DOI: 10.1119/1.1374249

Fiorella, L. \& Mayer, R.E. (2018). What works and doesn't work with instructional video. Computers in Human Behavior, 89. DOI: 10.1016/j.chb.2018.07.015

Flood, V.J., Amar, F.o.G., Nemirovsky, R., Harrer, B.W., Bruce, M.R. \& Wittmann, M. C. (2015). Paying attention to gesture when students talk chemistry: Interactional resources for responsive teaching. Journal of Chemical Education, 92(1), 11-22. DOI: 10.1021/ed400477b

Gilbert, J.K. (2008). Visualization: An emergent field of practice and enquiry in science education. In Visualization: Theory and practice in science education (pp. 3-24): Springer. DOI: 10.1007/978-1-4020-5267-5_1.

Guo, P.J., Kim, J. \& Rubin, R. (2014). How video production affects student engagement: An empirical study of MOOC videos. Paper presented at the Proceedings of the first ACM conference on Learning@ scale conference. DOI: 10.1145/2556325.2566239

Jeffery, K.A. \& Bauer, C.F. (2020). Students' Responses to Emergency Remote Online Teaching Reveal Critical Factors for All Teaching. Journal of Chemical Education, 97(9), 2472-2485. DOI: acs.jchemed.0c00736

Jing, H.G., Szpunar, K.K. \& Schacter, D.L. (2016). Interpolated testing influences focused attention and improves integration of information during a video-recorded lecture. Journal of Experimental Psychology: Applied, 22(3), 305. DOI: 10.1145/2556325.2566239 
Kollalpitiya, K.Y., Partigianoni, C.M. \& Adsmond, D.A. (2020). The Role of Communication in the Success/Failure of Remote Learning of Chemistry during COVID19. Journal of Chemical Education, 97(9), 3386-3390.

DOI:

10.1021/acs.jchemed.0c00772

Lagerstrom, L., Johanes, P. \& Ponsukcharoen, M.U. (2015). The myth of the six-minute rule: Student engagement with online videos. Paper presented at the Proceedings of the American Society for Engineering Education. DOI: $10.18260 /$ p.24895

Lee, M.W. (2020). Online Teaching of Chemistry during the Period of COVID-19: Experience at a National University in Korea. Journal of Chemical Education, 97(9), 28342838. DOI: $10.1021 /$ acs.jchemed.0c00881

Li, L.-Y. (2019). Effect of prior knowledge on attitudes, behavior, and learning performance in video lecture viewing. International Journal of Human-Computer Interaction, 35(4-5), 415426. DOI: $10.1080 / 10447318.2018 .1543086$

Mayer, R.E. (2014). Principles based on social cues in multimedia learning: Personalization, voice, image, and embodiment principles. The Cambridge handbook of multimedia learning, 16, 345-370. https://tinyurl.com/5abs2ys9

Mayer, R.E. \& Moreno, R. (2003). Nine ways to reduce cognitive load in multimedia learning. Educational psychologist, 38(1), 43-52. DOI: 10.1207/S15326985EP3801_6

McCusker, C.E. \& Mohseni, R. (2020). Reflections on Transitioning to Online General Chemistry in Southern Appalachia. Journal of Chemical Education, 97(9), 2913-2916. DOI: 10.1021/acs.jchemed.0c00743

Morgan, J. (2003). Lecturing for learning. A Handbook for Teaching and Learning in Higher Education: enhancing academic practice. $\mathrm{H}$. Fry, S. Ketteridge and S. Marshall. Abingdon, RoutledgeFalmer, 75-90.

Nordmann, E., Calder, C., Bishop, P., Irwin, A. \& Comber, D. (2019). Turn up, tune in, don't drop out: The relationship between lecture attendance, use of lecture recordings, and achievement at different levels of study. Higher
Education, $\quad 77(6), \quad$ 1065-1084. DOI: $10.1007 / \mathrm{s} 10734-018-0320-8$

Nordmann, E., Horlin, C., Hutchison, J., Murray, J.-A., Robson, L., Seery, M. \& Mackay, J. (2020). 10 simple rules for supporting a temporary online pivot in higher education. PLOS Computational Biology. DOI: 10.1371/journal.pcbi.1008242

Petillion, R.J., \& McNeil, W.S. (2020a). Johnstone's Triangle as a Pedagogical Framework for Flipped-Class Instructional Videos in Introductory Chemistry. Journal of Chemical Education, 97(6), 1536-1542. DOI: 10.1021/acs.jchemed.9b01105

Petillion, R.J., \& McNeil, W.S. (2020b). Student Experiences of Emergency Remote Teaching: Impacts of Instructor Practice on Student Learning, Engagement, and Well-Being. Journal of Chemical Education, 97(9), 24862493. DOI: $10.1021 /$ acs.jchemed.0c00733

Ranga, J.S. (2020). Factors Influencing Student Learning in Semi-Flipped General Chemistry Courses. Journal of Chemical Education, 97(8), 2130-2139. DOI: 10.1021/acs.jchemed.9b01165

Read, D., Barnes, S.M., Hughes, O., Ivanova, I.T., Sessions, A. \& Wilson, P. J. (2022). Supporting student collaboration in online breakout rooms through interactive group activities. New Directions in the Teaching of Physical Sciences, $17 . \quad$ DOI: 10.29311/ndtps.v0i17.3946

Read, D., Barnes, S.M., Hyde, J. \& Wright, J. S. (2019). Nurturing reflection in science foundation year undergraduate students. Teaching Chemistry in Higher Education: A Festschrift in Honour of Professor Tina Overton, 23. https://tinyurl.com/3zb6pz2t

Read, D., Watts, J.K. \& Wilson, T.J. (2016). Partial flipping to support learning in lectures. In The Flipped Classroom Volume 2: Results from Practice (pp. 55-79): ACS Publications. DOI: 10.1021/bk-2016-1228.ch004

Reid, N. (2019). A tribute to Professor Alex $H$ Johnstone (1930-2017): His unique contribution to chemistry education research. 
Chemistry Teacher International, 1(1). DOI: 10.1515/cti-2018-0016

Roediger III, H.L. \& Butler, A.C. (2011). The critical role of retrieval practice in long-term retention. Trends in cognitive sciences, 15(1), 20-27. DOI: 10.1016/j.tics.2010.09.003

Roth, W.M. \& Welzel, M. (2001). From activity to gestures and scientific language. Journal of research in science teaching, 38(1), 103-136. DOI: $10.1002 / 1098-$ 2736(200101)38:1\%3C103::AID-

TEA6\%3E3.0.CO;2-G

Sarju, J.P. (2020). Rapid Adaptation of a Traditional Introductory Lecture Course on Catalysis into Content for Remote Delivery Online in Response to Global Pandemic. Journal of Chemical Education, 97(9), 25902597. DOI: 10.1021/acs.jchemed.0c00786

Schacter, D.L., \& Szpunar, K.K. (2015). Enhancing attention and memory during videorecorded lectures. Scholarship of Teaching and Learning in Psychology, 1(1), 60. https://tinyurl.com/4jpyimfk

Schell, J., \& Mazur, E. (2015). Flipping the chemistry classroom with peer instruction. In J. Garcia-Martinez \& E. Serrano-Torregrossa (Eds.), Chemistry Education: Best Practices,
Opportunities and Trends. Wiley-VCH (pp. 319-343). https://tinyurl.com/9hw7t3xm

Szpunar, K.K. (2017). Directing the Wandering Mind. Current Directions in Psychological Science, 26(1), 40-44. DOI: $10.1177 / 0963721416670320$

Szpunar, K.K., Khan, N.Y. \& Schacter, D.L. (2013). Interpolated memory tests reduce mind wandering and improve learning of online lectures. Proceedings of the National Academy of Sciences, 110(16), 6313-6317. DOI: 10.1073/pnas. 1221764110

Van Gog, T. (2014). 11 The Signaling (or Cueing) Principle in Multimedia Learning. The Cambridge handbook of multimedia learning, 263. https://tinyurl.com/9y7dass4

Wang, J., Antonenko, P. \& Dawson, K. (2020). Does visual attention to the instructor in online video affect learning and learner perceptions? An eye-tracking analysis. Computers \& Education, 146, 103779. DOI: 10.1016/j.compedu.2019.103779

Wang, J. \& Antonenko, P. D. (2017). Instructor presence in instructional video: Effects on visual attention, recall, and perceived learning. Computers in Human Behavior, 71, 79-89. DOI: 10.1016/j.chb.2017.01.049 


\section{Appendix:}

\section{Section 1: Lecture provision}

Before the closure of campus, lectures were delivered in 50 minute sessions with Vevox questions incorporated for interactivity. Since closure, lectures are being delivered as a series of mini-lecture recordings with Panopto quiz questions embedded in them. A 'talking head' showing the lecturer is included in the recording.

1) What do you feel is the impact of shorter mini-lecture recordings on your learning in comparison to a 50 minute face-to-face lecture?

- Significant positive impact on my learning

- Small positive impact on my learning

- No impact on my learning

- Small negative impact on my learning

- Significant negative impact on my learning

- Please explain your answer to the previous question with reference to the benefits and/or disadvantages of breaking lecture recordings into shorter segments. (optional)

2) What do you feel is the impact of the inclusion of Panopto quiz questions on your learning in comparison to recordings with no quiz questions (e.g. flipped lectures from earlier in the year)?

- Significant positive impact on my learning

- Small positive impact on my learning

- No impact on my learning

- Small negative impact on my learning

- Significant negative impact on my learning

- Please explain your answer to the previous question with reference to the benefits and/or disadvantages of including quiz questions in recorded lectures. (optional)

3) What is the impact on your experience of providing a 'talking head' showing the lecturer in a recording in comparison to recordings with no 'talking head' (e.g. flipped lectures from earlier in the year)?

- Significant positive impact on my experience

- Small positive impact on my experience

- No impact on my experience

- Small negative impact on my experience

- Significant negative impact on my experience

- Please explain your answer to the previous question with reference to the benefits and/or disadvantages of including a talking head in recorded lectures. (optional)

4) What is the impact on your experience of providing lectures in an online format in comparison to attending face-to-face lectures on campus?

- Significant positive impact on my experience

- Small positive impact on my experience

- No impact on my experience

- Small negative impact on my experience

- Significant negative impact on my experience

- Please explain your answer to the previous question with reference to the benefits and/or disadvantages of online and face-to-face lectures. (optional) 
5) Which of the following statements most closely matches your experience?

- I'm spending much more time watching lecture recordings than I spend in lectures on campus

- I'm spending a little more time watching lecture recordings than I spend in lectures on campus

- I'm spending about the same amount of time watching lecture recordings as I would in lectures on campus

- I'm spending a little less time watching lecture recordings than I would spend in lectures on campus

- I'm spending a much less time watching lecture recordings than I would spend in lectures on campus

6) To what extent do you agree with the following statement?

"Lecture material should continue to be provided in the current format (i.e. online mini-lectures with Panopto quiz questions) when we return to on-campus teaching"

- Strongly agree

- Agree

- Neutral view

- Disagree

- Strongly disagree

- Please explain your answer to the previous question with reference to the benefits and/or disadvantages of the current approach in comparison to the 'normal' approach. You may also give your own suggestions for how best to provide lecture material to students. (optional)

\section{Section 2: Workshop provision}

Before the closure of campus, workshops took place on campus in two hour sessions with staff and demonstrators present to support students. Since closure, workshop activities have been made available online and 'talking mark scheme' videos have been provided. These videos provide guidance and tips to help students if they are stuck on an activity, as well as outlining the answers to the problems.

1) What do you feel is the impact on your learning of completing the workshop activities remotely, with reference to a talking mark scheme, as opposed to doing so in a taught session on campus?

- Significant positive impact on my learning

- Small positive impact on my learning

- No impact on my learning

- Small negative impact on my learning

- Significant negative impact on my learning

- Please explain your answer to the previous question with reference to the benefits and/or disadvantages of completing workshops in the current manner in comparison to being on campus. (optional)

2) To what extent do you agree with the following statement?

"The hints and tips in the talking mark scheme adequately compensate for not having a demonstrator present to ask for help"

- Strongly agree

- Agree

- Neutral view

- Disagree 
- Strongly disagree

- Please explain your answer to the previous question with reference to the benefits and/or disadvantages of completing workshops using a talking mark scheme in comparison to having a demonstrator to ask for help. (optional)

3) Which of the following statements most closely matches your view:

- I am generally completing more of the workshop material now than I did when we were on campus (including private study time)

- I am generally completing the same amount of workshop material now as I did when we were on campus

- I am generally completing less of the workshop material now than I did when we were on campus (including private study time)

4) To what extent do you agree with the following statement?

"Workshop material should continue to be provided in the current format (i.e. workshop activities completed by students with support from talking mark schemes) when we return to on-campus teaching"

- Strongly agree

- Agree

- Neutral view

- Disagree

- Strongly disagree

- Please explain your answer to the previous question with reference to the benefits and/or disadvantages of the current approach in comparison to the 'normal' approach. You may also give your own suggestions for how best to provide workshop material to students. (optional)

\section{Section 3: The logistics of studying at home}

1) The remote learning approach requires you to manage your own learning and the time you devote to it. Which of the statements below most closely matches your view.

- I like being able to manage my own learning and the time I devote to it

- Neutral view

- I don't like being able to manage my own learning and the time I devote to it

- Please explain your answer to the previous question with reference to the benefits and/or disadvantages of having to manage your learning and the time you devote to it. (optional)

2) Have you been able to make enough time in your weekly schedule to undertake your studies?

- I have had no problems finding the time I need to complete my studies

- I have had a few problems finding the time I need to complete my studies

- I have had significant problems finding the time I need to complete my studies

- I have not been able to undertake my studies at all due to other commitments

- Please elaborate on your response to the previous question. Remember that you can contact staff at any time if you are having problems. (optional)

3) To what extent are you studying with other students (e.g. working on workshop problems via video calls or other communication tools) while engaged in remote learning?

- I'm studying a lot with other students 
- I'm studying a little with other students

- I'm not studying at all with other students

- Please give some brief details about how you have been studying with others, or why you haven't been doing so. (optional)

4) What do you feel has been the impact of remote learning on your work-life balance?

- My work-life balance is significantly better than before

- My work-life balance is slightly better than before

- My work-life balance hasn't changed much

- My work-life balance is slightly worse than before

- My work-life balance is significantly worse than before

5) How do you feel about the amount of communication from staff?

- There is too much communication

- The amount of communication is about right

- There is too little communication

- Please add a comment on your answer to the previous question. (optional)

6) What has been your experience with the hardware you have been using to undertake your studies remotely?

- I have had the appropriate hardware to complete all tasks

- I have had the appropriate hardware to complete most tasks

- I have not had the hardware needed to complete most tasks

- I have not had the hardware to complete any tasks

7) What has been your experience with internet access while undertaking your studies remotely?

- I have had no problems with the internet

- I have had minor problems with the internet that have not significantly impacted my experience

- I have had problems with the internet that have sometimes had a negative impact on my experience

- I have had problems with the internet that have had a significant impact on my experience

- I have had problems with the internet that have made it impossible for me to engage meaningfully with remote learning

8) Overall, how do you feel about the provision of remote learning for the Chemistry module on the Science Foundation Year?

- Very happy

- Happy

- Neutral view

- Unhappy

- Very unhappy

9) Do you have any suggestions for improvements that might be made to the remote learning provision on the Chemistry module for future cohorts, should we need to use this approach again in the future? (optional)

10) Are there any other comments you would like to add in relation to remote learning on the Chemistry module or the Science Foundation Year more generally? (optional) 